\title{
Sea level height, sea surface temperature, and tuna yields in the Panama bight during El Niño
}

\author{
M. J. Pedraza ${ }^{1}$ and J. A. Díaz Ochoa ${ }^{2}$ \\ ${ }^{1}$ Programa de Magister en Ciencias, Mención Pesquerías, Departamento de Oceanografía, Universidad de Concepción, \\ Casilla 160-C, Concepción, Chile \\ ${ }^{2}$ Programa de Doctorado en Oceanografía, Departamento de Oceanografía, Universidad de Concepción, Casilla 160-C, \\ Concepción, Chile
}

Received: 24 May 2005 - Revised: 14 December 2005 - Accepted: 20 December 2005 - Published: 30 January 2006

\begin{abstract}
Between 1988 and 1998, annual tuna landings at Buenaventura (Colombian Pacific) are correlated with the sea surface temperature in the central Equatorial Pacific $(r=0.78$, $p<0.05)$ and the sea level height at Buenaventura $(r=0.76$, $p<0.05)$ and Balboa (Panama) $(r=0.79, p<0.05)$. Seasonal oceanic upwelling is forced by the Panama wind jet, which may favour oceanic fisheries such as tuna. Here we first apply a bivariate correlation method (Pyper and Peterman, 1994) and then a multivariate approach (principal components analysis or PCA) to investigate the relationships of these environmental variables with landings. With the first method, we find that landing is best correlated with the sea surface temperature in the Niño 3 region, whereas the other relationships are less clear. In contrast, with PCA we find that PC1 explains $90.6 \%$ of the total variance and suggests that sea surface temperature plays a major role in determining tuna availability in the area (especially during El Niño events). Since PC2 is mainly correlated with sea level height at Balboa but only represents $6.8 \%$ of the total variance, we suggest that oceanic upwelling effects on tuna landings at Buenaventura are not significant at interannual scales.
\end{abstract}

\section{Introduction}

Colombian marine fisheries capture a wide diversity of highvalue resources that are mainly destined for export (Beltrán and Villaneda, 2000). Between the 1950s and the 1980s, industrial fisheries grew substantially because of high yields of coastal penaeids. However, in the mid-1980s, prawn fisheries suffered a crisis at the same time that tuna fisheries increased. Thus, tuna is currently the most economically important resource in Colombia (FAO, 2003).

Tuna landings at Buenaventura Port correspond to yields obtained in the Pacific Ocean and are mainly composed of yellowfin tuna (Thunnus albacares) and skipjack (Katsu-

Correspondence to: J. A. Díaz Ochoa

(jadiaz@udec.cl) wonus pelamis). These two species are highly migratory and their distribution encompasses international waters as well as the border of the economic exclusive zone. The fleet is mainly constituted by purse seiners (400 tons or higher), which spend about 90 days fishing at sea. Other important species within the tuna yields are the big eye (Thunnus obesus) and Euthynus sp., mainly found in the Colombian jurisdictional waters and fished by smaller ships (FAO, 2003).

The El Niño Southern Oscillation (ENSO) phenomenon is considered the main cause for inter-annual climatic variability around the globe. The economies of many countries, mainly in tropical regions, depend on the presence of this phenomenon (Suarez et al., 2004). The abundance of various species of economically important fish such as tuna is highly related to water temperature and food availability. To a certain degree, the water movement related to ENSO determines the distribution of water temperature (Suarez et al., 2004).

The analysis of fishery and environmental variables has established that tuna distribution and abundance are closely associated with physical changes in the ocean such as temperature changes, storms (length and magnitude or intensity), and ENSO, as well as with variations in the mixing depth layer and disturbances caused by the wind (Blackburn, 1969; Ritter et al., 1982; Diaz, 1992; Lehodey et al., 1997; Chavez et al., 1999). Tuna concentrate in high productivity zones (such as upwelling zones, around islands, or at current interfaces) where they are attracted by food (Joseph, 1970; Lehodey et al., 1997), so relative densities of the fish follow the distribution of primary production with different time delays (Ritter and Guzman, 1982; Ortega, 1998). Tuna can be found between $17^{\circ} \mathrm{C}$ and $31^{\circ} \mathrm{C}$, although they are generally distributed in places where the temperature is above $20^{\circ} \mathrm{C}$ without considering the presence of food (Ortega, 1998). On a large scale, tuna distribution is determined by ocean temperature (Mullen, 1992). The tuna spawn between $26^{\circ} \mathrm{N}$ and $14^{\circ} \mathrm{S}$, and from the littoral to $140^{\circ} \mathrm{W} ; 85.3 \%$ of the spawning occurs between $26^{\circ} \mathrm{C}$ and $30^{\circ} \mathrm{C}$ (Ueyanagi, 1978; Schaefer, 1998). 
For the Colombian Pacific, Rodríguez and Stuardo (2002) studied the seasonal oceanic upwelling of the Panama Bight through the analysis of chlorophyll and wind satellite imagery and found that upwelling is stronger during the first trimester of the year, when north-eastern trade winds dominate. These authors suggested that upwelling may affect tuna availability for the fleet. However, more detailed information about this important resource in the Colombian Pacific is scarce. Consequently, the aim of this work is to study the influence of the El Niño events on tuna availability off the Colombian coasts between 1988 and 1998. We investigate the relationship between landing and environmental factors such as sea level height (SLH) and sea surface temperature (SST) in the equatorial Pacific at an interannual scale.

\section{Methods}

As indicators for the extreme phases of the El Niño Southern Oscillation (ENSO) cycle, we used the multivariate ENSO Index (MEI), which is based on six important variables observed in the tropical Pacific. These variables are sea level pressure, zonal and meridional components of the surface wind, sea surface temperature, surface air temperature, and total cloudiness of the sky, available from the Comprehensive Ocean-Atmosphere Data SET (COADS). The MEI is calculated as the first principal component of all six variables and is available from NOAA (Wolter and Timlin, 1993, http: //www.cdc.noaa.gov/people/klaus.wolter/MEI/mei.html)

\subsection{Data}

The data set corresponds to total tuna annual landings (tons) at Buenaventura Port (INPA, 1999). Although some 70\% of the tuna catch comes from the Pacific, most processing plants are located on the Atlantic coast (Beltrán and Villaneda, 2000); therefore, we accumulated landing statistics for both the Pacific and the Atlantic. Furthermore, we selected environmental variables that reflect the El Niño cycles such as the mean SLH at Buenaventura and at Balboa and the mean SST in the Niño 3 region within the Equatorial Pacific (the Niño 3 index) to estimate their correlation with landings. The time series of the Niño 3 index were obtained from NOAA (http://www.cpc.ncep.noaa.gov/data/ indices/) and SLH series from the University of Hawaii Sea Level Centre (http://www.soest.hawaii.edu/UHSLC/).

\subsection{Statistical analysis}

We used two methods to assess possible relationships between tuna landings and the environment, described below.

2.2.1 Univariate correlation method (Perry and Smith, 1994)

This method consists of calculating the difference between a relative cumulative frequency distribution (CFD) of the environmental variable $(\mathrm{x})$ and a weighted relative cumulative frequency distribution (WCDF) obtained by multiplying the CDF by tuna landings (y). If a relationship does not exist between the environmental variable and tuna landings, both the CDF and the WCDF should be parallel; otherwise both variables could be related. We used the following expression to compute the $\mathrm{CDF}$ :

$F(t)=\frac{1}{n} \sum_{i=1}^{n} I\left(x_{i}\right)$

where $\mathrm{n}$ is the number of observations and $\mathrm{I}\left(\mathrm{x}_{i}\right)$ is an indicator function defined as:

$I\left(x_{i}\right)=\left\{\begin{array}{ll}1, & \text { if } x_{i} \leq t \\ 0, & \text { otherwise }\end{array}\right\}$

with $t$ representing an index varying between the minimum and the maximum of the environmental variable (i.e. the range of the observations) at a step size appropriate for the desired resolution. We calculated the WCDF with the following expression:

$G(t)=\frac{1}{n} \sum_{i=1}^{n} y_{i} I\left(x_{i}\right)$

As a measure of the association between tuna landings and the environmental variables (e.g. Niño 3, sea level height), we used the maximum vertical distance $\max |G(t)-F(t)|$ and tested its statistical significance by bootstrapping the observed differences 2000 times and deriving an empirical distribution of probability to construct a $95 \%$ confidence interval (Perry and Smith, 1994; Páramo et al., 2003). Such an analysis was conducted using a MS-Excel macro provided by Gabriel Claramunt, University Arturo Prat (Iquique, Chile).

\subsubsection{Principal components analysis}

Once the previous steps were accomplished, we proceeded to analyze the combined effect of the environmental variables using a principal component analysis (PCA) (e.g. see Johnson and Wichern, 1998). With this method, we tried to describe the effects of the Niño 3 index $\left(Z_{1}\right)$, the SLH at Buenaventura $\left(Z_{2}\right)$, and the SLH at Balboa $\left(Z_{3}\right)$ by a few linear combinations of the original variables or principal components (PC). We used the correlation matrix of the variables to find the uncorrelated linear combinations that maximized the variance. Thus we had the random vector $\boldsymbol{Z}^{\prime}=\left[Z_{1}, Z_{2}, Z_{3}\right]$ and the correlation matrix $\boldsymbol{\rho}$, which had the eigenvalue-eigenvector pairs $\left(\lambda_{1}, \boldsymbol{e}_{1}\right),\left(\lambda_{2}, \boldsymbol{e}_{2}\right)$, and $\left(\lambda_{3}, \boldsymbol{e}_{3}\right)$, where $\lambda_{1} \geq \lambda_{2} \geq \lambda_{3} \geq 0$. Then the ith $\mathrm{PC}$ was given by:

$P C_{i}=\boldsymbol{e}_{i}^{\prime} \boldsymbol{Z}=\boldsymbol{e}_{i 1} Z_{1}+\boldsymbol{e}_{i 2} Z_{2}+\boldsymbol{e}_{i 3} Z_{3}, \quad i=1,2,3$

Each component of the vector $\boldsymbol{e}_{i}^{\prime}=\left[e_{i 1}, e_{i 2}, e_{i 3}\right]$ can be interpreted; the magnitude of $e_{i k}$ measures the importance of the variable $k$ to the ith PC independently of the other variables (Johnson and Wichern, 1998). To obtain the PCA, we used the varimax rotation and all the data set except 1989 and 1998, when SLH data were missing for Buenaventura. All the calculations were conducted with the Statistica 6.0 software (StatSoft, 2001). 

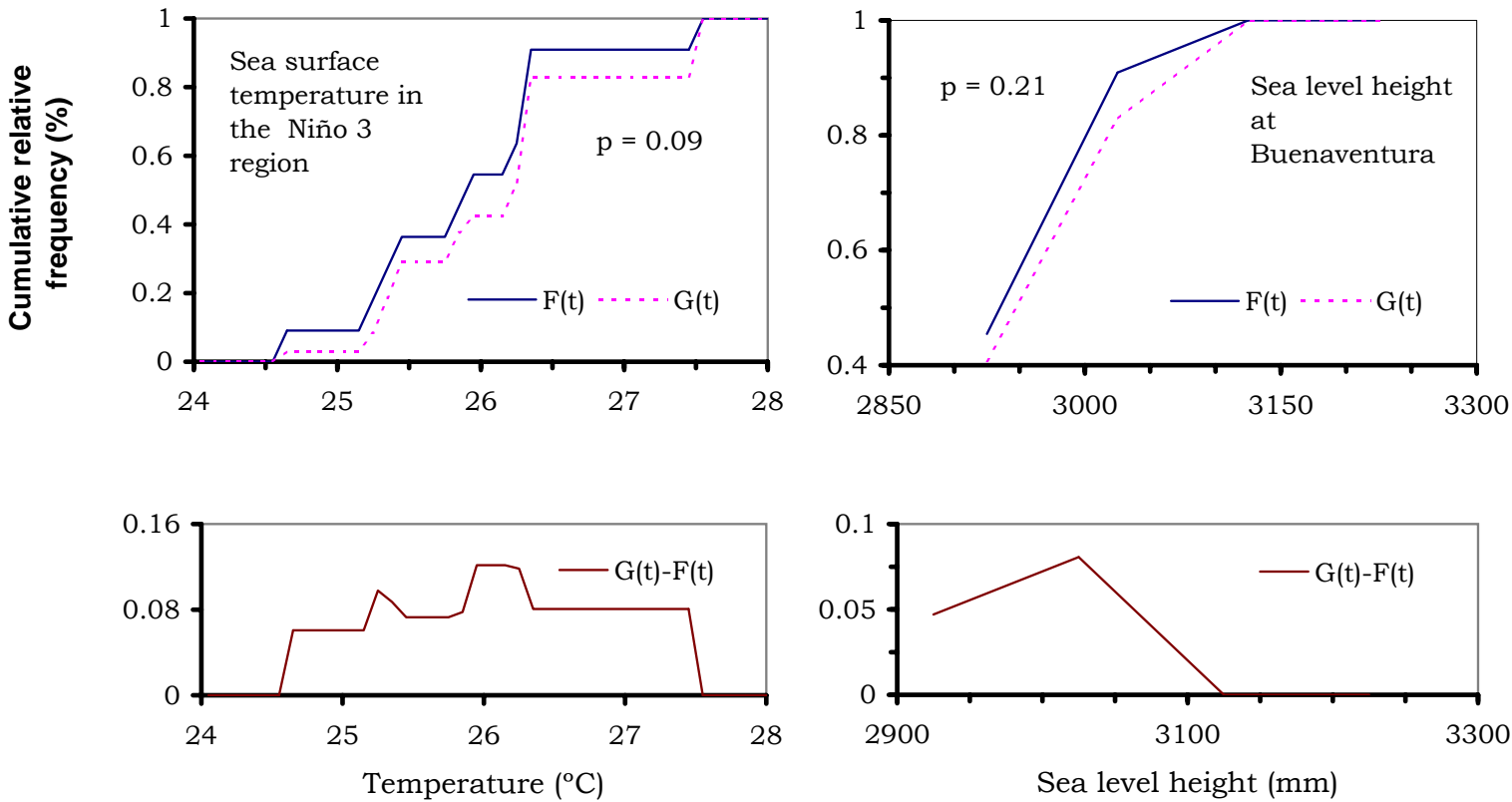

Fig. 1. Cumulative frequency distributions $F(t)$ of the mean sea surface temperature at El Nino 3 region in the Equatorial Pacific (left) and the sea level height at Buenaventura (right) between 1988 and 1998. $G(t)$ is a function corresponding to each $F(t)$ weighted by tuna landings at Buenaventura. The difference $G(t)-F(t)$ below each panel is used as a measurement of the association between the respective environmental variable and landings (Perry and Smith, 1994). The statistical significance levels, expressed by the $p$-values, were obtained with a boostraping methodology.

\section{Results}

Bivariate correlations with the method of Perry and Smith (1994) let us detect a high correlation (bootstrap probability $=0.09$ ) between the Niño 3 index and tuna landings. The other relationships (e.g. SLH at Buenaventura) were difficult to interpret and clear conclusions could not be drawn (Fig. 1). The maximum difference between $G(t)$ and $F(t)$ for the Niño 3-landing relationship showed that the association between both variables occurred when the sea surface temperature was greater than $26^{\circ} \mathrm{C}$ in the central Equatorial Pacific.

On the other hand, the PCA showed a clearer picture of the joint influence of the SLH at Buenaventura and Balboa as well as the Niño 3 index. The first PC explained $>90 \%$ of the total variance and all the three variables were highly correlated with it (Fig. 2, Table 1). On the other hand, PC2 only represented $6.8 \%$ of the variance and gave more importance to the SLH at Balboa. Moreover, PC2 revealed a contrast between SLH at Balboa and the Niño 3 and the SLH at Buenaventura, since they had opposite signs (Table 1). A bivariate plot of the PC2 vs. the PC1 showed that landings during the 1988-1989 La Niña and the strong 1997-1998 El Niño (ENSO events identified with the MEI criterion) were highly affected by these environmental variables and had different signs (Fig. 3). A linear regression model fitted to a scatter plot of landings vs. PC1 showed that there is a significant statistical relationship between both variables (Fig. 4, $r 2=0.65, p<0.05$ ).

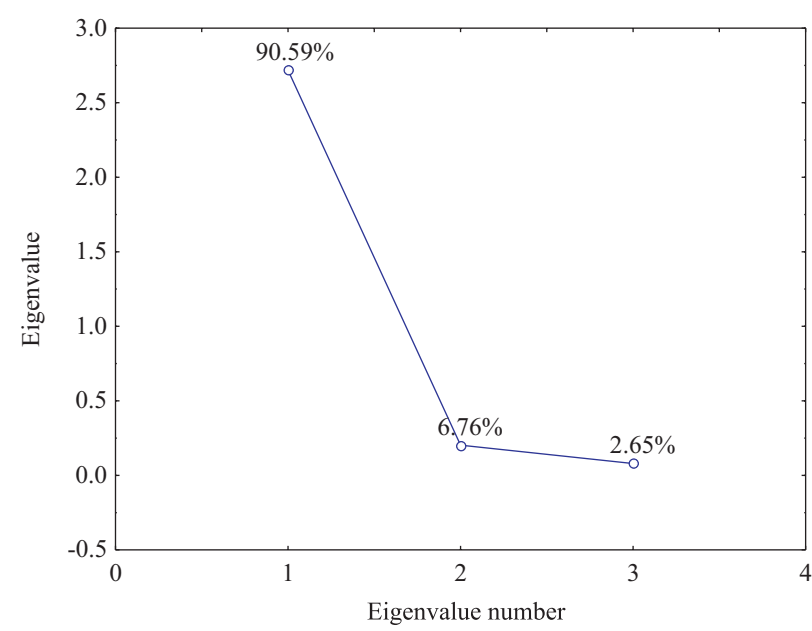

Fig. 2. Explained variance accounted for by the three principal components extracted from annual observations of the sea level height at Buenaventura (Colombia) and Balboa (Panama) and the Niño 3 index.

\section{Discussion}

ENSO events seem to be the main source of variability of tuna landings in Buenaventura during the 1990s. If we accept the first PC as a good index of environmental effects, about $65 \%$ of landing variance is accounted for by a simple linear model. Thus, landings in Buenaventura tend to be higher when PC1 decreases (i.e. high SLH at Buenaventura and Balboa and high SST at the Niño 3 region). 
Table 1. Factor loadings and their correlations with the original variables (in parentheses) from a principal components analysis for three environmental variables in the Tropical Pacific between 1988 and 1998. Principal component analysis was based on the correlation matrix. $\mathrm{SLH}=$ Sea Level Height at Buenaventura (Colombia) and Balboa (Panama). The Niño 3 Index is the mean sea surface temperature in the Niño 3 area within the Equatorial Pacific.

\begin{tabular}{lrrr}
\hline Environmental factor & Factor 1 & Factor 2 & Factor 3 \\
\hline NIÑO 3 Index & $-0.59(-0.97)$ & $0.32(0.15)$ & $0.74(0.21)$ \\
SLH at Balboa & $-0.56(-0.93)$ & $-0.82(-0.37)$ & $-0.09(-0.02)$ \\
SLH at Buenaventura & $-0.58(-0.96)$ & $0.47(0.21)$ & $-0.66(-0.19)$ \\
\hline
\end{tabular}



Fig. 3. Plot of the second principal component (PC2) vs. the first principal component (PC1) derived from annual observations of the sea level height at Buenaventura (Colombia) and Balboa (Panama) and the sea surface temperature at the Niño 3 region.

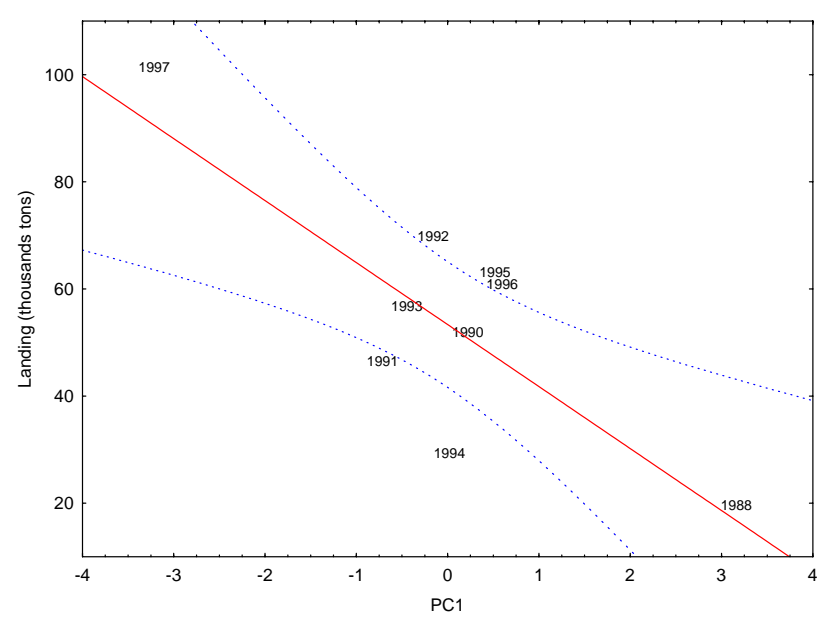

Fig. 4. Regression model fitted to a scatter plot of tuna landings at Buenaventura (Colombia) vs. the first principal component (PC1) derived from annual observations of the sea level height at Buenaventura (Colombia) and Balboa (Panama) and the sea surface temperature at the Niño 3 region.

PCA analysis also showed that the first PC can explain almost all the environmental variability, but this could be due to the influence of two strong El Niño/La Niña years that were highly correlated with PC1. The other years seemed to be more associated with PC2 and possibly with the interannual variability of the oceanic upwelling in the Panama Bight. The cumulative frequency method suggested a correlation between Niño 3 and tuna landings, but from a statistical point of view, this relationship was not significant at the standard 5\% level. This fact is probably a consequence of the reduced number of points available to check the association between the environment and tuna yields in the Panama Bight. This observation is supported by the fact that the p-value calculated with the boostrap method, although not statistically significant, was rather low $(\sim 9 \%)$. Thus, the present framework allows us to say that the PCA performed better than the univariate correlation method of Perry and Smith (1994) and showed that this multivariate technique is useful for detecting environmental associations even when data availability is limited.

We used landing statistics of tuna in Colombia as a proxy for abundance or availability of the fish in the Panama Bight. It would probably be better to have standardized landings by fishing effort. Unfortunately, fishing effort measurements were not available from the Colombian fishery agencies and, even if they had been, it is possible that these figures would not be accurate since the tuna fishery in the eastern tropical Pacific encompasses a very broad oceanic area. On the other hand, data is available from the Interamerican Tropical Tuna Commission (IATTC) about the total number of ships equipped with purse seines in this area. These statistics show that, between 1991 and 1998, the number of purse seiners remained quite constant (average: 176; coefficient of variation: $\sim 9 \%$ ) (IATTC fide: NOAA, Southwest Regional Office, Long Beach, CA, USA: http://swr.nmfs.noaa. gov/appendices.pdf). Therefore, landings could be a good indicator of tuna abundance or availability since fishing effort has remained rather constant during the studied period.

Looking at the PC biplot, we can say that some of the years lie at quite a distance from each other. In particular, 1997 and 1988 were very different years; 1997 corresponded to a very strong El Niño event and 1988 to one of the eight strongest La Niña events since 1949 (according to the MEI index). Thus, on an interannual scale, our analyses support the hypothesis that tuna landings at Buenaventura were determined mostly by the ENSO cycle, at least during the 1990s. Because the second PC explains very little of the variance of 
the environmental variables used here and is mainly associated with the SLH at Balboa, we suggest that on an interannual scale, the upwelling in the Panama Bight plays only a secondary role in determining tuna availability in the study area. This conclusion agrees with observations made in earlier works such as that of Forsbergh (1969, p. 140), who found that annual variations of the yellowfin and skipjack tuna abundances were not significantly related to annual variations in the upwelling intensity in the Gulf of Panama.

However, the relationship between the ENSO cycles and tuna yields in the Panama Bight could not be as simple as the results presented so far seem to show. From an historical perspective, purse seine fisheries started in the late 1950s and increased quickly until the mid 1980s. But since the 1982-1983 El Niño event, tuna yields dropped substantially and the fleet moved to the western Pacific. CPUE and cohort analyses showed that the exploited biomass of the yellowfin tuna decreased between 1973 and 1982, but began to increase again, reaching a maximum by 1985 . Tuna landings peaked in 1988 and have varied little since (Bayliff, 2003) It also seems probable that the abundance of tuna in the Equatorial Pacific obeys the long term trends of the global climate. In this context, the maximum tuna landing (1985) occurred at the end of a 25-year warming period (Sharp, G., http://sharpgary.org/fisheriesTimeline2.html). Therefore, future research should study longer time series and investigate the spatial variability of key environmental variables such as sea surface temperature and food distribution in the Panama Bight in relation to tuna distribution and its relationship with climate on different time scales. Furthermore, since tuna is a highly migratory resource, Colombian fisheries administration should be more involved in cooperative studies with neighbouring countries.

Acknowledgements. This study was funded by the project EPCOR of the Interamerican Institute for Climate Change (IAI) and the Graduate School of the University of Concepción. We thank to the reviewers for helpful comments and suggestions that led to an improved manuscript.

Edited by: P. Fabian and J. L. Santos

Reviewed by: W. Arntz and another referee

\section{References}

Bayliff, W. (Ed.): The quarterly report (January-March 2003) of the Inter-American Tropical Tuna Commission, Informal report of the status of eastern Pacific tuna fisheries, La Jolla, California, 35 pp., 2003.

Beltrán, C. S and Villaneda, A. A.: Perfil de la pesca y la acuicultura en Colombia. Subdirección de investigaciones, Instituto Nacional de Pesca y Acuicultura - INPA, 29 pp., 2000.

Blackburn, M.: Conditions related to upwelling which determines distribution of tropical tunas off western Baja California, Fishery Bulletin, 68, 147-176, 1969.

Chavez, F. P., Strutton, G., Friederich, G. E., Feely, R. A., Feldman, G. C., Foley, D. G., and McPhaden, M. J.: Biological and Chem- ical Response of the Equatorial Pacific Ocean to the 1997-98 El Niño, Science, 286, 2126-2131, 1999.

Díaz, P. J.: Modelado de las pesquerías de túnidos en el Pacífico mexicano (Atún aleta amarilla) Ms. Sc. Thesis, UNAM, México, 72 p., 1992.

FAO: Resumen informativo sobre la pesca por países. Organización de las Naciones Unidas para la Agricultura y la Alimentación, FID/CP/COL, REV., 6, 33-65, 2003.

Forsbergh, E.: On the climatology, oceanography and fisheries of the Panama Bight, Inter-American Tropical Tuna Commission Bulletin, 14(2), 49-258, 1969.

INPA (Instituto Nacional de Pesca y Acuicultura): Boletín Estadístico Pesquero 1997-1998, Ministerio de Agricultura y Desarrollo Rural, Bogotá, 114 p., 1999.

Johnson, R. A. and Wichern, D. W.: Applied multivariate statistical analysis, Upper Saddle River, N. J., Prentice-Hall, 816 p., 1998.

Joseph, J.: Management of tropical tunas in Eastern Pacific Ocean, Trans. of the Amer. Fish. Soc., 99, 629-648, 1970.

Lehodey, P., Bertignac, M., Hampton, J., Lewis, A., and Picaut, J.: El Niño Southern Oscillation and Tuna in the Western Pacific, Nature, 389, 715-717, 1997.

Mullen, A. J.: Reaction diffusion models for dynamics distribution of yellowfin tuna, Ph.D. Thesis, University of London, 127 pp., 1992.

Ortega, G. S.: Análisis de las fluctuaciones espacio temporales en la abundancia de atún en el Océano Pacífico Oriental. Fac. de Ciencias, UNAM, 186 pp., 1998.

Páramo, J., Quiñones, R. A., Ramirez, A., and Wiff, R: Relationship between abundance of small pelagic fishes and environmental factors in the Colombian Caribbean Sea: an analysis based on hydroacoustic information, Aquatic Living Resources, 16, 239 245, 2003.

Perry, R. I. and Smith, S. J: Identifying habitat associations of marine fishes using survey data: an application in the Northwest Atlantic, Can. J. Fish. Aquat. Sci., 51, 589-602, 1994.

Ritter, W. and Guzmán, S.: Efectos meteorológicos y oceanográficos en la productividad del Océano Pacifico del Este, Geofísica, 17, 23-39, 1982.

Ritter, W., Klimek, R., and Guzmán, S.: Sobre la abundancia, distribución y comportamiento del atún aleta amarilla en el Océano Pacifico del Este y su correlación a condiciones físicoambientales, Geofísica, 17, 6-22, 1982.

Rodríguez, E. and Stuardo, J.: Variability of photosynthetic pigments in the Colombian Pacific Ocean and its relationship with the wind field using ADEOS-I data, Proceedings of the Indian Academy of Sciences: Earth and Planetary Sciences, 111, No. 3, 227-236, 2002.

Schaefer, K. M.: Biología reproductora del atún aleta amarilla (Thunnus albacares) en el océano Pacifico Oriental, InterAmerican Tropical Tuna Comm. Bulletin, 21, 222-272, 1998.

StatSoft, Inc.: STATISTICA (data analysis software system), version 6, www.statsoft.com, 2001.

Suarez, S. J., Ritter, O. W., Gay, G. C., and Torres, J. J.: ENSOtuna relations in the eastern Pacific Ocean and its prediction as a non-linear dynamic system, Atmósfera, 245-258, 2004.

Ueyanagi, S: Recent tune culture research in Japan, Ocean Develop. Conf., 5(CI), 23-29, 1978.

Wolter, K. and Timlin, M. S.: Monitoring ENSO in COADS with a seasonally adjusted principal component index, Proc. of the 17th Climate Diagnostics Workshop, Norman, OK, NOAA/N MC/CAC, NSSL, Oklahoma Clim. Survey, CIMMS and the School of Meteor., Univ. of Oklahoma, 52-57, 1993. 